\title{
Creysse - Les Rivelles
}

\section{Frédéric Prodéo}

\section{OpenEdition \\ Journals}

Édition électronique

URL : http://journals.openedition.org/adlfi/4062

ISSN : 2114-0502

Éditeur

Ministère de la culture

Référence électronique

Frédéric Prodéo, «Creysse - Les Rivelles », ADLFI. Archéologie de la France - Informations [En ligne], Aquitaine, mis en ligne le 01 mars 2009, consulté le 19 avril 2019. URL : http://

journals.openedition.org/adlfi/4062

Ce document a été généré automatiquement le 19 avril 2019

(c) Ministère de la Culture et de la Communication, CNRS 


\title{
Creysse - Les Rivelles
}

\author{
Frédéric Prodéo
}

Date de l'opération : 2009 (EX)

1 À l'emplacement de deux futures maisons individuelles sur la même parcelle située au sommet du plateau du Pécharmant, deux opérations de diagnostic successives ont été réalisées. Elles ont permis de reconnaitre une couverture pléistocène bien dilatée, dans une séquence sédimentaire pouvant atteindre $4 \mathrm{~m}$ d'épaisseur et qui va en se dilatant vers l'ouest, en relation avec la proximité d'une doline. Elle se développe sur le calcaire altéré, recouvert d'argile de décarbonatation, livrant des blocs de silex brut, qui définit un gîte de matière première.

2 La séquence pléistocène se caractérise par des formations argileuses striées de fentes verticales de dessiccation. Vers $1,3 \mathrm{~m}$ de profondeur, un horizon graveleux (de type « grain de sel ») est formé au détriment de nappes fluviatiles très anciennes et issu de l'érosion des points culminants alentours. Celui-ci contient des produits lithiques du Paléolithique moyen, dans un mauvais état de conservation. Un second niveau anthropisé se trouve à la base des argiles recouvrant les formations graveleuses, où le mobilier présente un meilleur état de fraîcheur.

3 L'examen technologique et typologique de la série permet de proposer une attribution au Moustérien ancien. Cette occupation s'intègre aux données sur l'environnement Paléolithique, récoltées par ailleurs dans le voisinage, notamment en relation avec la RN 21.

Prodéo Frédéric 
INDEX

operation Expertise (EX)

Index géographique : Aquitaine, Dordogne (24), Creysse

Index chronologique : Paléolithique moyen

Thèmes : argile, industrie lithique, sédimentologie, silex 